\title{
The Effects of Suspicion on Interorganizational Relationships: An Abstract
}

\author{
Gina Brynildsen
}

\begin{abstract}
This conceptual paper explores suspicion in interorganizational relationships and its effects on governance strategies and relational outcomes. Suspicion is delineated from trust and distrust, and a definition of interorganizational suspicion is offered. Three types of interorganizational suspicion - suspicion of behavior, suspicion of capabilities, and suspicion of intent - are proposed. A conceptual model for the effects of interorganizational suspicion on governance strategies and relational outcomes is developed based on theoretical and empirical support across a variety of disciplines. This paper adds to the growing literature on the dark side of business relationships by exploring the effects of different types of suspicion on interorganizational relationships and offers insights into how suspicion can be mitigated or resolved before it escalates into high distrust and relationship termination.
\end{abstract}

References Available Upon Request

G. Brynildsen $(\bowtie)$

Florida Atlantic University, Boca Raton, FL, USA

e-mail: glavagna@fau.edu 